\title{
Branca de Neve e os Sete Pixels: um estudo sobre imagem digital
}

\section{Lenara Verle}

Bachare em Comunicação Social pelaUFRGS Designer doLaboratório Eletrônico deArte\& Design (LEAD) da UFRGS eartista digital

\section{A imagem digital}

A IDÉIA decodificar imagensatravés dedígitos já foi ensaiada diversas vezes antes de se chegar à forma de bits de computador. Começando pel os mosaicos romanos e passando pelos singelos bordados de nossas avós, podemos citar exemplos que vão desde a pintura pontilista (que formava as imagens através de pontos discretos ao invés de tons contínuos) atémanifestações demassa recentes como a "ola" praticada em arquibancadas de estádios, onde cada pessoa sentada se assemelha a um bit, que pode ocupar duas posi ções: abaixado ou levantado, transmitindo a imagem de uma onda pela alternância coordenada dessas posi ções.

Hoje porém, com os computadores largamente disseminados pelo mundo, o termo "imagem digital" já virou sinônimo de "imagem de computador". Existem mil hões dessas imagens ao nosso redor. Do computador elasvão paraaTV, os jornais, livroserevistas, viajando pelos fios telefônicos, satélites ou mesmo pelo ar. A o serem digitalizadas elas adquiremnovas possibilidades demanipulação e transporte residentes no computador. Se transformam em "entes digitais."

A maneiramaissimplesdeseobter uma imagem digital é criá-la dentro do computador, com tela e pincéis digitais, por assim dizer. Uma imagem feita fora do computador, com ferramentas tradicionais, precisa ser codificada, ou seja, digitalizada para que o computador possa entendêla.

Fotografias (ou mesmoavidareal) mostram um infinito número de tons decinza e/ ou cores, onde os vários tons - quevão desde o branco completo ao preto completo - seguem-se continuamente sem interrupções.

Ao contrário das pessoas, o computador trabal ha com números enão com tons de 
cinzae/ ou cor. Paraconverter as informações decor ebrilho dasimagensembitssãousados scanners e digitalizadores de vídeo.

O scanner coloca uma grade invisível sobre a imagem original elêa informação de luminosidade, contraste e cor em cada lugar da grade. Os números resultantes em cada local são atríbuídos a um pixel (picture element, menor unidade de uma imagem digital). Asinformações decadaum dospixels daimagemsãoreunidasparacriar umamatriz de pixels. Essa matriz contém informações sobre: localização de cada pixel na matriz $(x, y)$, tom decor ou decinza, brilho econtraste.

Osaplicativos ${ }^{1}$ (programas ou software) deanálisedeimagem são criados pararealçar e manipular as matrizes de pixels. Essas manipulações são feitas mudando a informação dos pixels da imagem segundo funções matemáticas desenvolvidas especialmente para esse fim, produzindo efeitos possíveis de se rem realizados pelos meios tradicionais e também outros quenão podem ser conseguidos por nenhum outro meio.

O computador poderealizar, emsegundos, operações feitas tradicionalmente com as imagens, desde procedimentos simples como a acentuação do contraste (altocontraste) até outros complicados como a harmonizacão dos tons de cinza (sistema de zonas), para citar al guns exemplos encontrados na fotografia.

Ele pode também realizar efeitos inéditos para os quais são inventados nomes sugestivos como Pixelstorm, Jade Tuboid Ripples, Paint Alchemy ou Xaos Tools. ${ }^{2}$

Uma vez dentro do computador, a imagem pode parecer igual, mas na real idadeela jásetransformou profundamente. Elaagoraé umentevirtual. Seas artes gráficas no mundo digital guardam algumas semel hanças com as artes tradicionais, há também profundas diferenças entre elas.

O artista digital sedepara com um novo universo à sua frente. Um universo onde as leisqueconhecemosnãofuncionamequepor ser muito jovem e estar constantemente em expansão, necessita ser explorado. A princípio, asferramentas queesseartistavai encon- trar se assemelham àquelas tradicionais às quai seleestáacostumado. Natela do computador há pequenos pincéis elápis, paletas de tintas com milhões de opções, compassos, réguas e muitos outros objetos familiares. Paraacessá-lospodeser utilizadauma caneta especial que desliza sobre uma mesa magné tica e se assemelha a uma caneta comum al guns model os até escrevem de verdade.

Com apenas um comando podem ser executadas operações como preencher uma área com tinta, mudar as cores, deformar, clonar, borrar, girar, inverter ou acionar efeitos variados.

A diferença fundamental porém, é que se está pintando não com telas e tintas, mas com bits. Enquanto a imagem está sendo criada ela existeapenas virtual mente, na memória volátil do computador. A penas quando as operações são salvas em um disco magnéticoelasadquirem umacertamaterialidade. Mesmo assim, se ol harmos nas entranhas de um bitencontraremosapenasalgunselétrons em trilhas magnéticas. Não há pigmentos ou tecido, apenas uma sequência dezeroseuns.

A imageménaverdadeumarquivo, um conjunto de dados digitais que, lido por um software, adquire a forma de pixels coloridos na tela. Essa dinâmica influi no processo criativo do artista digital. Ele pode gravar (e assim congelar) qualquer estágio de uma sequência de manipulações, e então testar várias possibilidades a partir das quais chegará à obra final - ou obras finais. A criação deixa de ser um processo linear e passa a oferecer múltiplas ramificações durante a construção de uma obra.

Mesmo depois de considerada acabada pelo artista, el a nunca está acabada realmente, pois tudo é potencialmente um começo para novas obras. A pril Greiman, uma das primeiras artistas a utilizar o computador Macintosh fala:

"A tinta nunca seca no Universo do Mac. Você pode parar de trabalhar em uma peça a qualquer hora que quiser. Mas você pode também, anos depois, ressucitar um documento e trabalhar 
nelecomosenuncativesseparado. Tudo estásemprevivo." (Greiman 1990, p.57)

No mundo virtual onde reside a imagem digital, os efeitos denossas atitudes não são duradouros e irreversíveis como o são muitas vezes no mundo real.

No topo dos menus de opções de qualquer aplicativo se encontra algo impressionante chamado undo. Como o próprio nome diz, esse comando desfaz a última operação que foi feita.

É o tempo voltando atrás.

Alguns aplicativos permitem até noventa enove undos, e o mesmo número de redos, ou seja, refazer o quefoi desfeito. Erros podem ser corrigidos com um cliqueapenas, ou provocados delibera-damente para testar os efeitos que desencadeiam:

“O comando undo permite a você retirar al go queacabou defazer, sem deixar traços. Ou, com outro clique, devolvêlo. A maneira tradicional de pensar chamaria isto de uma bela maneira de corrigirerros. Naverdade, vocêaprende a pensar nisto como uma maneira de produzir erros. Erros são acidentes, e acidentes muitas vezes revelam possibilidades inesperadas." (Greiman 1990, p.57)

A lém da maleabilidade da imagem digital, possibilitada pelo suporte virtual no qual é armazenada, ela também apresenta uma outra característica muito importante, a facilidade de interagir com outras imagens digitais, advinda do código binário no qual é armazenada.

Hoje em dia toda a informação que nos cerca está sendo cada vez mais armazenada sob a forma digital.

“A grande conquista do período Neolítico, ou da 'pedra nova' (8.000 a $1.500 \mathrm{AC}$ ) foi o desenvolvimento decomunidades permanentes e da agricultura. A conquista do Neossilicato (de 1971, quando foi fabricado o primeiro microprocessador, atéos dias dehoje) é a Revolução digital.

A noção de que todos os nossos dados sobre o universo - desde a assinaturadeumasupernova emraios $X$ até as texturas visuais de um Van Gogh podem ser transpostas para o código binário é uma das idéias mais úteis, emocionantes e arrogantes que a nossa espéciejáproduziu.... O modelobinário hoje informa cada um dos campos da ciência e da mesma maneira está redefinindo a cultura contemporânea." (Grennwald 1993, p.25) sobreisso:

O designer gráfico Eric Martin fala

“O significado da palavra 'implodir' é 'irromper para dentro'. Esta definição captura o espírito ea dinâmica da revolução digital e o seu profundo impacto em disciplinas existentes, entreoutras o design gráfico. Eu digo 'entre outras', cautel osamente, uma vez que o efeito mais amplo desta revolução é o de tornar várias coisas muito mais próximas do quejá estiveram desdequea revolução industrial fez de todos nós especialistas: idéiaerealização, produtor ediente, criação erevisão, palavra/ imagem/ $\mathrm{som} /$ movimento. Em resumo, a tecnologia digital não respeita os limites existentes, sejam eles espaciais, temporais, conceituais ou profissionais." (in Greiman 1993, p.10)

Oslimitesimpostospelo suportefísico deixam de existir à medida em que tudo é planificado em um mesmo suporte digital.

As possibilidades se abrem para que coisas antes díspares possam interagir entre si.

É a aproximação de que fala Martin.

O artista digital tem ao seu alcance qualquer coisa que possa ser convertida em código digital e consequentemente em imagem para servir de matéria prima para o seu trabalho. 


\section{A imagem mutante}

Não édifícil imaginar o conceito de uma obra de arte mutante que vá sofrendo várias traduções, interferências ereleituras deartistas diversos de uma forma contínua como na brincadeira infantil do telefonesem fio, onde a mensagem vai se tranformando até não guardar nenhuma ou quase nenhuma semeIhança com a mensagem original.

Com a tecnol ogia das redes de computadoresquehojeinterligamogloboépossível que artistas de vários lugares do planeta realizem uma espécie de telefone sem fio visual a partir deum banco de imagens colocado à disposição de todos dentro da rede.

Exemplos dessetipo deexperimentação artística estão sendo criados pelo P rojeto Sito. (www.sito.org)

O Projeto Sito é uma galeria de arte digital etambém umacomunidadevirtual de artistas que se reúnem através da Internet. ${ }^{3}$

A partir dasferramentas disponíveisno "mundo digital" onde os participantes estão inseridos, são criados projetos artísticos que envolvemainteração deváriaspessoas. Essas obras de arte habitam um universo virtual, hiperdimensional (ao contrário do nosso mundo material tridimensional) e povoado de "programas-robôs", que vão construindo as "paredes" e"sal as" desseuniverso àmedida que as imagens criadas pelos artistas são transferidas para o computador central do Projeto Sito.

Chamado de trabalho colaborativo (collaborative work) pelos idealizadores dos projetos, este tipo de iniciativa aponta para uma cooperação entre produtores de imagens, em um contexto onde não há direitos autorais: apósal gumas dezenas dealterações não se pode dizer mais quantos e o quanto de cada artista há em uma obra; e qualquer imagem podeser usada como ponto departida para novas (re)criações.

O computador aparece nesse contexto não apenas como mais uma ferramenta, mas como algo mais complexo, algo que se assemelha a uma meta-ferramenta que denominamos hardware e com a qual se fabricam então outras ferramentas, denominadas software ou "ferramentas moles" por alguns, e que vão ser manipuladas pelos usuários. Várias figuras aparecem aí concorrendo para o resultado final obtido no processo artístico mediado por computador. A quem cabe, então, a autoria deuma obra digital? A o computador e aos engenheiros de hardware? Aos criadores do software? Ao artista que os manipulou? Ou ainda, no caso de uma obra interativa, ao receptor que a atualizou?

Segundo Machado, "a melhor maneira de dar respostas a problemas dessa espécie talvez seja relativizar a contribuição detodas as inteligências e de todas as sensibilidades queconcorrem para configurar a experiência estética contemporânea”. Para ele, “isto implica, é claro, em uma desmistificação de certos valores convencionais ou até mesmo arrogantes, inspiradosnaidéia dequea 'obra' seria o produto de um gênio criativo individual, que ocuparia uma posição superior na hierarquia de competências do fazer artístico" (Machado 1993,p.40)

\section{A imagem interativa}

Sempre existiu uma forma simples de interatividade que é o olhar subjetivo do espectador frente a uma obra, capaz de produzirinfinitasinterpretações diferentes. Com a tecnologia digital, porém, torna-se possível produzir uma obra com níveis muito mais al tos de interatividade. Onde o espectador transformado em ator e autor - vá escolhendo, enquanto a obra está send o feita, as possibilidades e desdobramentos que conduzirão ao seu resultado final, único e personalizado deleitura.

Uma das experiências dearteinterativa realizadas pelo Projeto Sito é a Tela Infinita.

"A Tela Infinita é um exemplo de arte digital bem diferente do que estamos acostumadosa ver. Primeiro porqueela não é feita por uma só pessoa, mas por várias. Depois porque ela nunca fica 'pronta', masestácontinuamentesendo 
modificada e 'ampliada'. Por ser feita coletivamente através da Internet, pessoas do mundo todo podem participar da sua criação.

Além disso, ela se expande não para cima ou para baixo, mas em profundidade. Sua área é fixa, e o que vai sendo acrescentado são variações em partes da imagem. É como um quebracabeça a ser montado onde existem várias peças que se encaixam para cada uma das posições.

Quem escolhe as peças que formama imagem éo ‘observador' da tela. Se desejar, o espectador também pode participar da criação dos pedaços que compõem a tela, ou então apenas escoIher a(s) sua(s) tela(s) preferida(s) entre os pedaços disponíveis.

A tualmente existem 86,4 bilhões de combinações possíveis para a Tela Infinita. O objetivo do projeto écontinuar crescendo, atéeventualmenteseaproximar da infinitude." (Verle 1996)

Em um exemplo desses o leitor coloca tanto desi na obra quanto o autor. Na verdade eles podem até se encontrar na rua e se chamar de "parceiros", poiso leitor temà sua disposição muitas das possibilidades de que o autor lançou mão na confecção da obra, que na verdade é uma obra em potencial, uma obra aberta. Quem éo verdadeiro autor? Não importa, o queestá secriando éa possi bilidadedecriar. Stuart Brand, um dos diretores do $M$ edia Lab no MIT, editor da revista W ired e membro da Electronic Frontier Foundation fala sobre isso:

“Criar em um novo meio sempre traz à tona esta possibilidade. Vocêpodeestar criando um meio em si mesmo. Você pode estar criando a possibilidade de criar. Eis algo pelo qual vale a pena arriscar o anonimato." (Brand 1993: p.230)

$\mathrm{Na}$ verdade, a obra interativa se asse melha muitas vezes a um jogo, pois ao prazer da fruição se incorpora o prazer da descoberta e da criação. A o invés do distanciamento que se manifesta na apreciação de uma imagem tradicional, há uma participação, uma penetração que passa a fazer parte do prazer estético naapreciação deuma obrainterativa. A imagem troca sua materialidade estável por uma maleabilidade anônima. Sobe, briIha e se esvanece junto com os refluxos do meio onde está inserida, refletindo a instantaneidade deste, efêmera edescartável como tudo na cultura pós-moderna. A tingindo o auge de sua reprodutibilidade técnica, a obradearteadquireumcaráter eminentemete lúdico, coletivo e anônimo.

Seo conceito deautoria entraemcheque com a entrada da mediação da máquina no fazer artístico, experiências como as de obras deartecolaborativaseinterativasamplificam essa discussão, potencializando o número de autores/ receptores(ospapéisseconfundem) envolvidos na criação da obra, até virtualmente dissolver qualquer certeza sobre a sua autoria.

A releitura(chamemosassimnafalta de um termo melhor) aparece como objetivo explícito daartecolaborativa, mastambém pode ser encontrada em menor escala em diversas situações do nosso dia a dia. Isso épropiciado em parte pelo ambiente digital e pela planificação de suportes queeletraz, tornando possível incorporar facilmentereferências ecitações visuais de várias fontes a uma obra, principalmente através dos digitalizadores de imagem.

O computador enfatiza o que antes já acontecia corriqueiramente. Nada mais comum do que um artista ou designer ultilizar outra(s) obra(s) como inspiração, fazendoa(s) transparecer em sua criação. Agora se torna fácil incorporar o próprio objeto da inspiração diretamente na obra, como uma espécie de "inspiração instantânea”.

Osmateriaisusadosna criação denovas imagens podem provir de diversas fontes, desdeojornal do diaatéobrasclássicas, dando origemaumaconstantereciclagemeevolução. Segundo Mikhail Bakhtin, “durante a vida póstuma, as obras vão se enriquecendo com 
significadosnovos, vão deixando deser oque eram em seu tempo para dar respostas às novas perguntas que as gerações sucessivas Ihe fazem" (in Machado 1993, p.198). ${ }^{4}$

Mais do que um arroubo iconoclasta, como o era na época da revolução cultural modernista, a apropriação deobras deoutros autoreséumfato corriqueiro nos dias dehoje, apesar deainda vermosarautos do romantismo promoverem o resgate da obra original, receptáculo da aura falada por Benjamin, ou em uma perspectiva mais prosaica, homens de lei a reclamarem o direito soberano do autor sobre sua obra, estes últimos aparecendo com muito mais freqüência, respaldados por leis de copyright ainda da era pré-digital.

Mas afinal, como determinar o que é uma obra original? Talvez essa pergunta não faça mais sentido hoje em dia. Além da impossibilidade teórica, ainda há uma impossibilidade prática de se determinar a chamada originalidadedeuma obra. Segundo Arlindo Machado, qualquer tentativanessesentidose aproxima perigosamente dos labirintos de Borges:

“Toda a noção de falsificação, plágio, adulteração eoutros quejandos pressupõea idéia deum 'original' fetichizado, imutável e absoluto em relação ao qual divergem as réplicas. . . . são frágeis as tentativas práticas de determinar com precisão a materialidade do original ea pertinência de sua originalidade. Uma vez que são imprecisas e escorregadias as provas que nos conduziriam a um original imaculado, diante do qual as falsificações poderiam ser finalmente desmascaradas, só podemos concluir daprecariedadedosnossoscritériospara decidir sobre a autenticidade dos fatos dacultura. Antes, talvez fossemais produtivo considerar os fenômenos da falsi ficação eda adulteração como expressões legítimas da cultura humana, sem os quais a atividade criadora se veria paralisada sob o tacão de uma pretensa ética da criação."(Machado 1993, p.199)
Se a falsificação pura e simples de uma obra é algo duvidoso de ser estabelecido, muito mais difícil é determinar que referências foram usadas em sua elaboração, que constitui-sesemprenum processo decolagem e releitura de outras obras, e que pode se estender por várias gerações de imagens, indefinidamente.

Além disso, o original mencionado por Machado finalmente desaparece para além de qualquer dúvida quando as imagens são transportadas para um suporte digital, perdendo de certa maneira a sua materialidade.

Hoje em dia são encontradas posições radicais em favor de uma declaração de obsolescência do direito autoral baseada nessa característica de virtual idade da obra digital. Segundo Stuart Brand:

“É o paradoxo da novidade: nada fica velho de uma hora para outra. O que vem rápido vai rápido. Algumas pessoas fazem arte para a imortalidade. É preciso desistir disso quando se trabaIha com novos meios de vanguarda. Tudo é escrito em vento. Como diz na Newsletter da Electronic Frontier Foundation, 'I mpressoeme étrons 100\% reciclados'." (Brand 1993, p.139)

A imaterial idadequeo meio digital proporciona à obra de arte vem ao encontro das idéias modernistas que pregavam a livre reciclagemnaarte. Antesbombardeadosapenas por idéias abstratas, agora nos deparamos com a concretude da imaterialidade à nossafrente. Ondecolocar antigosmitos como o dafotografiacomo retrato daverdadequando a manipulação de imagens (fotográficas ou não) está ao alcance de qualquer um e é utilizada corriqueiramante nos meios de comunicação? Como identificar a originalidade entresucessivas gerações declones, manipulações, rel eituras .... Como estabelecer uma fronteira entre o real e o simulacro, se a percepção passa necessariamente pela representação e pela subjetividade, e o meio homogeiniza e torna anônima a mensagem?

As imagens que povoarão nosso futuro 
serão digitais, mutantes, interativas. Mas, o queisso significa?Talvez estejamos nosaproximando deumamaneiraum pouco diferente de pensar e de fazer a cultura. N ormal mente relegada a um pano de fundo histórico, a tecnologiapodealavancar mudanças profundas na sociedade. Estamos hoje no início de uma revolução tão importante quanto a que Gutenberg desencadeou, no fim da idade média. Por trás da revolução digital desponta uma revolução cultural, ao que parece, com fôlego para atingir grandes proporções.

Os profissionais de artes gráficas e comunicação, como agentes ativos do fazer cultural, devem estar atentosesintonizadoscom essas mudanças e com as novas possibilidades trazidas por elas, paramel hor explorá-las e para melhor compreenderem o meio em que estão inseridos, assim cumprindo o seu papel de estudiosos e produtores da cultura contemporânea .

\section{Notas}

1 Modernamente se usa o termo aplicativo, ao invés de programa. Isto porque o software não émais apenas um conjunto de instruções predeterminadas executadas pelo computador para produzir um resultado. Antes, éumaarquitetura abertade opções que vão sendo escolhidas interativamente pelo usuário enquanto o documento estásendo criado. Na prática, porém, os dois termos podem ser considerados sinônimos, sendo que programa é o mais conhecido pela maioria das pessoas.

2 Essesnomessãotiradosdekitsdeefeitosgráficosdisponíveis hojeno mercado chamados plug-ins, poisfuncionam conectados a "tomadas" existentes nos aplicativos de desenho sendo vendidos separadamente. Seus nomes poderiam ser traduzidos como TempestadedePixels, Ondulaçõoes Tubóides Cor deJade, Pintura Alquímica e Ferramentas do Caos.

3 A Internet é uma meta-rede que interliga hoje perto de oitenta milhões de computadores e cerca de cem milhões de usuários em vários países. Parasaber mais sobrea rede Internet eopapel do profissional decomunicacãonarede, recomendamos Kehoe, 1992 e Severo, 1993, respectivamente. Ambos constam das referências bibliográficas no final deste trabalho.
4 BAKTIN, Mikhail. Speech Genres and others Late Essays. Austin, University of Texas Press, 1975, p.5

\section{Referências Bibliográficas}

BATELLE, John. "The Next Big Thing: Live Picture". Wired 1.4 September/ October 1993.

BRAND, Stuart. "Creating creating". Wired Online, file 1.1/ departments/ idees.fortes. from infobot@wired.com, 1993.

BROWNING, John. "What is the role of libraries in the Information Economy?" Wired Online. file 1.1/ features/ libraries. from infobot@wired.com, 1993.

BYRNE, Chuck. "A Designer's Guide to the Computerized Studio, or, How to Stop Worrying and Start Exploiting the Tools of Desktop Publishing". Print, May/ June 1988.

COUCHOT, Edmond. "Definitions". Palestra de 15 de abril de 1992. Revue Virtuelle, notebook n²1, 1992.

DAVIS, Fred. "I Want My (Desktop) MTV!". Wired 1.3. July/ August, 1993.

FLOWER, Joe. "3DO: Hip or Hype?". Wired 1.2. May/June, 1993.

GREENWALD, Jeff. "Seven Wired Wonders". file wired.wonders from infobot@wired.com, 1993.

GREIMAN, April. Hybrid Imagery: The fusion of technology and graphic design. New York: Watson-Guptill Publications, 1990.

GRUBER, Michael. "Digital Archeology". Wired 1.5, November1993.

KEHOE, Brendan P. Zen and the Art of Internet. 1st ed: Prentice Hall, 1992.

LATANISION, Ivan; SCHMID Sacha. "es.p.r.i.t. Made Easy". es.p.r.i.t. vol. 2, n-2, 1990.

MACHADO, Arlindo. Máquina e Imaginário: 0 desafio das Poéticas Tecnológicas. São Paulo: Editora da Universidade de São Paulo, 1993. 
MONTZ, Kim. Color It! U ser M anual. 2ª ed.: MicroFrontier Inc., 1992.

OLABARRIAGA, Śllvia Delgado. Computação Gráfica: U ma $V$ isão G eral. Anotações para o seminário de mesmo nome. Porto Alegre, 1991.

SEVERO, Carlos Henrique. 0 papel do profissional de comunicação nas redes de computadores. Monografia de conclusão do curso de Comunicação Social (ênfase em jornalismo), Porto Alegre, 1993.

SYNERGY: Crosswireftp:/ / sunsite. unc.edu/ pub/ multimedia/ pictures/OTIS/ CROSSWIRE/README.TXT.

THE OTIS Project: The Operative Term Is STIMULATE. ftp:/ / sunsite.unc.edu/ pub/ multimedia/ pictures/ OTIS/ README.TXT.

VERLE, Lenara. Tela Infinita. http:/ / www.sito.org/ grid/ infgrid/. 